\title{
Performance appraisal and career counselling for senior house officers
}

\author{
M P Ward Platt, J M Parkin
}

\begin{abstract}
A pilot scheme of appraisal and career counselling for senior house officers (SHOs) in the Northern region has been undertaken. There were two sets of guidelines for the conduct of these interviews, one was a list of topics and the other a modification of the Manchester rating scale. All appraisal interviews were evaluated separately by the participating SHOs and consultants. There was strong concordance between these evaluations irrespective of the format chosen. Almost all participants considered that the interviews were useful, resulted in a fair assessment of performance, and fulfilled the stated aims of the scheme.
\end{abstract}

\section{Background}

In contrast to the attention paid to the career development of vocational trainees in general practice, ${ }^{12}$ training in the hospital based specialities has continued to rely on the apprenticeship principle. Discussions between consultants and junior staff about performance or career plans at present take place irregularly, if at all. In the absence of a formal mechanism we doubt whether most senior house officers (SHOs) at the end of their attachments have any real idea of their competence or their suitability for continuing to train in the specialty.

In the proposals for Achieving a Balance it was explicitly suggested that careers advice and counselling should be formalised, ${ }^{3}$ and the General Medical Council has made a similar point. ${ }^{4}$ Furthermore, we have been aware of pressure from SHOs for feedback about their performance.

A pilot scheme of formal assessment and counselling was therefore introduced for paediatric SHOs throughout the Northern region and its usefulness, judged by both consultants and junior staff, was evaluated.

\footnotetext{
Department of Child Health, The Medical School, Framlington Place Newcastle upon Tyne, NE2 4HH M P Ward Platt J M Parkin Correspondence to: Dr Ward Platt.
}

\begin{abstract}
Methods
The aims and objectives are given in appendix 1 .

Guidelines for the conduct of assessment interviews were requested by consultants and two different formats were devised. The first (appendix 2) was a simple checklist of the key topics that probably ought to be covered. The second (appendix 3) was a development (for particular use with SHOs in paediatrics) of the Manchester rating scale (modified Manaims, and provided a fair assessment of their performance; only two thought that it was threatening, and six felt strongly that it was not. Though one third of the respondents claimed that they had received important new insights into their performance, only one agreed that it would make a substantial difference to future practice, and four felt strongly that it would not. Six SHOs did not agree that they had received adequate career counselling, but two of these were general practitioner trainees who had already made their career decisions.
\end{abstract}

chester scale). ${ }^{5}$ This scale, developed from another rating scale originally designed for trainees in orthopaedic surgery, ${ }^{67}$ has been widely used to assess the performance of general practitioner trainees in their practices and in hospital attachments.

Neither set of guidelines was regarded as necessary for the achievement of the aims and objectives, and it was left to the individual consultant to choose. Copies of the two guidelines and a letter explaining the scheme were sent to the senior consultant paediatrician in each hospital in the region, together with evaluation forms.

\section{EVALUATION}

The purpose was to assess how far the consultant and the SHO felt that the aims and objectives of the assessment and counselling interview had been fulfilled. To enable paired evaluation, both the consultant and the SHO were asked to complete an evaluation form.

\section{Results}

At least one form was returned from 12 of the 17 hospitals that took part. From a total of 34 interviews there were 26 from SHOs, 28 from consultants (from 18 different consultants), and 20 paired evaluations.

Of the 34 interviews, 16 used the checklist format, 13 used the modified Manchester scale, three used a mixture of both, and two used neither.

Of the 18 consultants, nine used the checklist, five used the modified Manchester scale, two used both, and two used neither.

\section{RESPONSES FROM SHOS}

Most of the SHOs (table) believed that the assessment session was useful, fulfilled the 


\begin{tabular}{|c|c|c|c|c|}
\hline & \multicolumn{2}{|l|}{ SHOs } & \multicolumn{2}{|c|}{ Consultants } \\
\hline & Disagree & Agree & Disagree & Agree \\
\hline $\begin{array}{l}\text { You found the session a threatening experience } \\
\text { You found the session a useful experience } \\
\text { The stated aims of the session were fulfilled } \\
\text { The session will make a considerable difference to }\end{array}$ & $\begin{array}{r}24 \\
2 \\
2\end{array}$ & $\begin{array}{r}2 \\
22 \\
22\end{array}$ & $\begin{array}{r}26 \\
3 \\
1\end{array}$ & $\begin{array}{r}1 \\
23 \\
24\end{array}$ \\
\hline $\begin{array}{l}\text { aspects of your practice in the next few months } \\
\text { The session covered all pertinent issues } \\
\text { The session resulted in a fair assessment of your }\end{array}$ & $\begin{array}{r}18 \\
3\end{array}$ & $\begin{array}{r}1 \\
22\end{array}$ & $\begin{array}{r}17 \\
3\end{array}$ & $\begin{array}{r}6 \\
24\end{array}$ \\
\hline $\begin{array}{l}\text { performance } \\
\text { You received important new insights into your }\end{array}$ & 3 & 19 & 2 & 20 \\
\hline $\begin{array}{l}\text { performance } \\
\text { Adequate counselling was given about your career }\end{array}$ & $\begin{array}{r}12 \\
6\end{array}$ & $\begin{array}{r}9 \\
14\end{array}$ & $\begin{array}{r}14 \\
5\end{array}$ & $\begin{array}{r}8 \\
17\end{array}$ \\
\hline
\end{tabular}

'Agree' includes 'strongly agree'; 'disagree' includes 'strongly disagree'.

RESPONSES FROM CONSULTANTS

Consultants who had interviewed several SHOs showed little variability in their evaluations of the interviews and the pattern of their responses (table) was similar to that from the SHOs. One consultant, however, wrote that 'It is ... unrealistic to think that consultants can actually make informed comments on many aspects of an SHO's performance since they are simply not in attendance most of the time'.

The only divergences between consultants and SHOs were about career counselling: there were three instances (from different hospitals) where the consultant said that counselling had been adequate, but the SHO disagreed.

\section{Discussion}

The modified Manchester scale provides an unambiguous description of best and worst performance in each of the dimensions of practice covered. Clearly, no SHO is likely to be located entirely at one or other end of the range. When originally developed by McGuire, ${ }^{6}$ and subsequently modified by Freeman and Byrne, ${ }^{5}$ each dimension was to be graded on a 12 point scale by both the trainer and the trainee; this was not to add up a score at the end (summative function), but to provide a focus for the interview and a semiquantitative basis for the assessment (formative function). It was decided that any attempt to score the SHOs could be misinterpreted, so the modified Manchester scale was used without scoring.

Use of the checklist might have resulted in a shorter interview, and discussion of the listed topics would probably not have been threatening to either the consultant or the SHO. No other input would be needed. On the other hand, when compared with the modified Manchester scale it is clearly less comprehensive, and makes avoidance of potentially uncomfortable discussions (such as manner with patients or interprofessional relationships) easy. These may, however, be the particular areas of practice that most need constructive criticism.

Use of the modified Manchester scale should provide more exhaustive discussion of the SHO's strengths and weaknesses, and might be expected to make avoidance of uncomfortable issues less easy. It would also require reasonably detailed knowledge of the SHO's practice by the consultant, however, and possibly some infor- mation from other members of staff. It would be of some interest to make a controlled comparison of the two styles of guidelines, but this was not part of the present study.

Data from the twice yearly surveys of all the junior paediatric SHOs and registrars in the Northern region (unpublished observations) have shown that certain departments perform poorly in providing what the junior staff consider to be acceptable postgraduate training. In the present study no evaluations were received from these departments. The bias in response was therefore towards those departments already known to be the best at providing for the needs of their junior staff.

Community based consultants were offered the same assessment guidelines as those in hospital practice. Not surprisingly, although the concept found favour, some of the guidelines were thought to be inappropriate. New guidelines for use by community paediatricians have been written (appendix 4), but not yet evaluated.

The timing of assessment is clearly of great importance. The SHO must have been in post long enough for a fair assessment to be possible, but must still have enough time to show that improvements in performance have taken place after the appraisal. Two assessments, one early in the third month of the post and one in the last month, would probably be the ideal. It might also be useful to provide SHOs with a copy of the modified Manchester scale at the beginning of the post.

However laudable the use of SHO assessments might be, they stand or fall by the degree to which consultants are able to make a realistic and objective assessment of their juniors' performance. It is disturbing that one of the responding consultants felt unable to comment upon this.

Having originally been developed for hospital use, the modified Manchester scale needed little modification to make it suitable once again for hospital paediatrics, but alternative methods of assessment have been proposed that may also be considered appropriate. One such model is described by Leonard, ${ }^{8}$ who compiled a list of over 300 items about which he considered a trainee should have a working knowledge, 'confidence' about each item being rated on a five point scale. This was to identify deficits in knowledge or skills, thereby allowing the training programme to focus on them. Such 
an approach could be applied to many disciplines, but would provide a rather narrow and mechanical view of medical practice.

Formal aptitude testing uses questionnaires to quantify personality, aptitude, and attainment. ${ }^{9}$ As it does not involve a dialogue, it has a purely summative function. The modified Manchester scale has elements in common with aptitude testing, but assumes that improvements in performance may take place; not only is it formative, but assessment is based on performance in a post rather than on paper. It also considers the adequacy of the SHO's training programme: consultants may expect to receive direct feedback about the quality of the training they are giving.

Most of the consultants and SHOs who took part in this study found the exercise rewarding and useful, irrespective of the format used. The Paediatric Education Committee now encourages consultants in the region to conduct assessment and counselling interviews for their SHOs, ideally twice during their paediatric attachment.

\section{Appendix 1 Aims and objectives of appraisal AIMS}

(1) To permit the paediatric SHO to receive an objective evaluation of his overall effectiveness.

(2) To create a formal opportunity for the consultant to elicit any problems that the SHO may be having in achieving effectiveness, and to suggest solutions for these.

(3) To provide an opportunity for career counselling, particularly for those SHOs intent on a career in hospital paediatrics.

(4) To enable the SHO to state how far the job satisfies his perceived training needs, and to suggest ways in which any shortcomings might be made up.

OBJECTIVES

(1) To give the SHO a clear picture of his current performance.

(2) To give an SHO who is not up to standard a chance to improve.

(3) To give the SHO an indication of his suitability to proceed further in paediatric training. (4) To give the consultant a clear picture of the SHOs' opinions about their posts.

\section{Appendix 2 List of topics to be covered during a session \\ HISTORY TAKING SKILLS}

The ability to talk to parents, to communicate with children, and to build relationships with them.

\section{EXAMINATION SKILLS}

The ability to examine competently neonates (both preterm and full term), infants, and children, and to make a basic assessment of development.

\section{PRACTICAL KNOWLEDGE}

Familiarity with appropriate drugs and other treatments, immunisation regimens, fluid requirements, infant feeding, and management of common disorders.

\section{THEORETICAL KNOWLEDGE}

The possible complications of common paediatric disorders, uncommon but important diseases, and the physiological basis of paediatric diseases and their management.

\section{MANUAL SKILLS}

The siting of intravenous infusions, intubation of neonates, lumbar puncture, venepuncture, arterial puncture, and examination without tears.

EXPLAINING TO PARENTS AND CHILDREN The nature and prognosis of the illness, and the nature and meaning of investigations.

RELATIONSHIPS WITH OTHER DOCTORS Consultation with more senior paediatricians, handing over to colleagues, and relationships with doctors in other specialties.

RELATIONSHIPS WITH NURSES AND MIDWIVES The ability to learn from people who have much to teach an inexperienced SHO.

\section{RELATIONSHIPS WITH OTHER MEMBERS OF THE TEAM}

Understanding the importance of the contributions of-for example-social workers, physiotherapists, and teachers.

THE IMMEDIATE AND LONG TERM CAREER PLAN OF THE SHO

THE ADEQUACY OF BOTH FORMAL AND INFORMAL TEACHING AND TRAINING

\section{Appendix 3 Modified Manchester rating scale}

(1) HISTORY AND EXAMINATION

This criterion is concerned with the SHO's enthusiasm for, and ability and skill in, gathering the information necessary for making diagnoses or decisions, or both.

The unacceptable SHO follows no routine of history taking. He fails to identify or does not bother to develop salient leads. He will not pursue alternative hypotheses. He does not seek information about clinical, psychological, and social factors, and he does not listen to the child. His recording is sketchy and not systematic.

The ideal SHO takes a comprehensive clinical, social, and behavioural history, and listens to the child. He examines patients thoroughly with appropriate techniques, and obtains much important information by careful observation of the child. He records his information carefully and uses previous and continuing records. 
(2) SOLVING PROBLEMS

This is concerned with the SHOs talent for, and skill in, using the information he had gained to develop a diagnosis and support his clinical decisions.

The unacceptable SHO does not fully realise the implications of the data that he collects. $\mathrm{He}$ is unable to interpret the unexpected result, which he may often ignore, and his thinking tends to be rigid and unimaginative therefore impeding his recognition of associated problems. His general shortcomings: rigidity of thought and lack of capacity to range flexiblythat is, 'diverge' when thinking over a particular problem-inhibit his effectiveness.

The ideal SHO realises the importance of unexpected findings and seeks to interpret them. He understands the nature of probability and uses this to assist his diagnosis and decision making. He takes all data into account before making a decision and routinely tests alternative hypotheses. He thinks effectively-he can range or 'diverge' in search of relevant factors in connection with the particular problem in hand-and he can also focus, or 'converge' his thinking on whatever factors are thought to be relevant.

\section{(3) ATTITUDES TOWARDS CHILDREN}

This concerns the SHO's ability to take account of the special needs of children.

The unacceptable SHO does not attempt to build a relationship with the child. He admits children to hospital unnecessarily, does not encourage them to play a part in taking the history, and carries out a brusque examination that upsets the child. He is dishonest with the child about uncomfortable investigations and procedures and does not make use of sedatives, analgesics, and local anaesthesia in appropriate circumstances. He has unrealistic expectations of children's behaviour, and is unable to cope when a child is difficult.

The ideal SHO builds relationships with children by talking to them in a manner appropriate for their development, encourages them to play a part in history taking, and makes use of games before and during formal examination. He tries to avoid admission to hospital when it may not be appropriate, and keeps the stay as short as possible, taking parental needs into account. He minimises the use of venepuncture; organises investigations efficiently; and uses appropriate sedation, anaesthesia, or analgesia whenever needed. He tells the child in appropriate language about his illness and its investigation.

\section{(4) RELATIONSHIP WITH PARENTS}

This is concerned with the SHO's effectiveness in working with parents.

The unacceptable SHO relates poorly to parents through aloofness, discourtesy, indifference, or pressure of work. He has difficulty in understanding their anxieties, fails to give them confidence in him, and may alarm them unnecessarily. He does not understand hostile or aggressive behaviour in parents, and retaliates with defensive or antagonistic behaviour.
He fails to show compassion for either the child or the parents.

The ideal SHO gives the parents confidence, and relieves their anxieties. Parents appreciate his commitment to their child's well being. Though he is honest with parents, he does not attempt to explain or prognosticate further than his experience permits. Parents like him and feel that he does not mind answering questions or discussing problems.

\section{(5) EMERGENCY CARE}

This is concerned with the SHO's ability to act effectively in an emergency.

The unacceptable SHO panics easily, takes ineffective measures, and fails to summon help from senior colleagues when necessary. $\mathrm{He}$ is unable to delegate tasks, becomes confused, and has difficulty in establishing priorities.

The ideal $S H O$ can make a quick assessment, and establish priorities with full regard to lifesaving procedures. He is aware of the consequences of delay. He obtains and organises the assistance of others, realises his own limitations, and summons expert help when required.

\section{(6) RELATIONSHIPS WITH COLLEAGUES}

This is concerned with the SHO's ability to work effectively with colleagues as members of a team.

The unacceptable SHO has difficulty with personal relationships, and lacks the ability to give and take instruction gracefully. He tends to be tactless or inconsiderate. He is unable to inspire confidence or cooperation in those with whom he works. He is unwilling to seek the assistance of more experienced medical or nursing staff. He does not support colleagues in their contacts with patients.

The ideal SHO gets on well with other people. $\mathrm{He}$ is conscious of the need for teamwork and fits in well as a member of a team. He seeks help when appropriate and respects the views of others. He acknowledges the contributions of others. He creates an atmosphere of 'working with' not 'working for' in other people. He possesses self control.

\section{(7) PROFESSIONAL VALUES}

This is concerned with the SHO's attitudes and standards as an individual member of the medical profession.

The unacceptable SHO is bad at communicating, he attempts to conceal his errors from his colleagues, and he shows no insight into his professional limitations. He is difficult to locate in emergencies and fails to hand over continuing problems adequately when going off duty. $\mathrm{He}$ is slovenly in his appearance.

The ideal $S H O$ is kind, courteous, and humble, and maintains a professional demeanour. He reports honestly, acknowledging his own errors. He respects the confidences of colleagues and patients, and places care of the patient above personal considerations. He recognises his own professional capabilities and limitations. 
(8) OPPORTUNITIES FOR TRAINING

This is concerned with the SHO's attitude to, and use of, postgraduate educational facilities.

The unacceptable $\mathrm{SHO}$ reads neither books nor journals. He remains passive and unquestioning on ward rounds, and makes no attempt to attend teaching sessions-either from his own consultants or at the general postgraduate meetings within his hospital. He does not take opportunities to attend outpatient clinics, $x$ ray conferences, or case conferences, and shows no interest in regional postgraduate teaching.

The ideal $S H O$ reads widely and takes an active part in routine ward rounds. He attends teaching sessions as often as possible and gives these a high priority-if necessary he organises teaching for himself. He makes use of opportunities to sit in on specialist clinics, attends case conferences, and tries to attend relevant regional courses.

\section{(9) CAREER DEVELOPMENT}

This is concerned with the environment within which the SHO provides a clinical service and receives education and training.

The unacceptable post is one in which, for reasons beyond his control, the SHO has such a heavy workload that a good performance on the preceding criteria is difficult. Working with little supervision, he has no example to follow as a paediatrician, few checks on his clinical management, and no time to read. No paediatric postgraduate teaching is organised locally, and no study leave is allowed. The SHO leaves the post having seen much clinical material but has profited little by this experience.

The ideal post is one in which teaching is accorded a high priority. Teaching sessions and clinical meetings are carefully organised and full participation is expected. The SHO is given appropriate supervision, and informal teaching is an everyday experience. He is able to reflect on most of the clinical problems he meets, and leaves the post with a deeper understanding of children in health and illness.

(10) OVERALL COMPETENCE

This concerns your judgment of the SHO's overall competence, taking into account criteria 1 to 8 inclusive.

\section{Appendix 4 Rating scale for community paediatric SHOs}

(1) GATHERING OF INFORMATION

The unacceptable SHO takes only a minimum medical history, does not seek information on behavioural or social aspects, does not inquire about problems in the rest of the family, does not seek information from other professionals, and his records are not kept legibly or logically.

The ideal SHO collects information of social as well as medical aspects of the case; considers social and behavioural factors; seeks information from all sources; recognises the value of information from the general practitioner, the health visitor, the school nurse, other professionals, and members of family; and his records are kept legibly, logically, and in problem oriented format.

(2) FORMULATION OF PROBLEMS

The unacceptable SHO may not recognise the existence of the problem, formulates the problem in a limited way with over emphasis on the medical aspects, is a convergent thinker, and fails to recognise environmental components.

The ideal SHO recognises when there is a problem; formulates medical, behavioural, and social components; recognises environmental and family components; and is a divergent thinker.

\section{(3) PLANNING}

The unacceptable $\mathrm{SHO}$ has a poorly organised work pattern; cannot plan work in advance, causes inconvenience to colleagues, and is poor or incompetent at coordinating group activities.

The ideal SHO organises his work effectively, maintains timetables well and plans work several weeks ahead in conjunction with nursing colleagues, and coordinates multidisciplinary activities effectively.

\section{(4) HANDLING OF CHILDREN}

The unacceptable $\mathrm{SHO}$ is poor at gaining children's confidence, does not talk readily with children or put them at their ease, does not describe procedures or gain their cooperation, and upsets babies by rough handling.

The ideal SHO has an easy manner with children, talks with them readily and gains their confidence, describes procedures and gains cooperation, and is gentle and considerate in handling babies.

\section{(5) TALKING TO PARENTS}

The unacceptable SHO does not perceive parents' anxieties, does not explain procedures or findings, uses complex technical language, and has an unsympathetic manner.

The ideal SHO perceives parents' fears and anxieties, explains procedures and findings without being asked in a way they can understand and has a sympathetic and interested manner.

(6) WORKING WITH OTHER PROFESSIONALS The unacceptable SHO does not cooperate readily with health workers from other disciplines, or understand their role; overuses medical authority and prefers to maintain management within medical discipline; he plans actions without perceiving their effect on other disciplines.

The ideal $S H O$ is relaxed in working with members of other disciplines and understands their role while ensuring they understand his; he does not attempt to dominate, or overuse medical authority.

(7) RECOGNITION OF IMPORTANCE OF HEALTH ISSUES

The unacceptable SHO fails to perceive the many social and environmental components of health, and is not aware of the contribution of other disciplines to maintaining health. 
The ideal SHO understands the environmental and political components of health, and the network of disciplines that contribute to improving health.

\section{(8) OPPORTUNITIES FOR TRAINING}

The unacceptable SHO reads neither books nor journals; remains passive and unquestioning and makes no attempt to attend teaching sessions either by consultants or at general postgraduate meetings; does not attend outpatient clinics, $x$ ray conferences, or case conferences, and shows no interest in regionally organised postgraduate teaching. He does not take up opportunities to attend multidisciplinary teaching sessions.

The ideal SHO reads widely and takes an active part in teaching; attends teaching sessions as often as possible and gives these a high priority-if necessary organising the teaching himself. He makes use of opportunities to sit in on specialist clinics, attends case conferences, and tries to attend relevant regional courses, and attends any multidisciplinary teaching available.

\section{(9) OVERALL COMPETENCE}

This concerns your judgment of the SHO's overall competence taking into account criteria 1 to 8 inclusive.

The authors thank all the consultants and SHOs who participated, and $\operatorname{Dr} A J R$ Waterston, consultant community paediatrician for providing a version of the modified Manchester scale for use with SHOs in community posts.

1 Statutory Instrument No 1644, National Health Service Act 1977, sections 30, 31, 32. London: HMSO, 1977.

2 Grey DJP. A system of training for general practice. Occasional paper 4. London: Royal College of General Practitioners, 1979.

3 United Kingdom Health Departments, the Joint Consultants Committee and Chairmen of Regional Health Authorities. Hospital medical staffing: achieving a balance. A plan for action. London: HMSO, 1987.

4 Education Committee, General Medical Council. Recommendations on the training of specialists. London: General Medical Council, 1987:16-19.

5 Freeman J, Byrne PS. The assessment of postgraduate training in general practice. 2nd ed. Guildford: Society for Research into Higher Education, 1976.

6 McGuire CH. An evaluation model for professional education medical education. Chicago: College of Medicine, University of Illinois, 1967.

7 Gregory CF. Grading systems: the American board of orthopedic surgery. In: Gilbert JAL, ed. Proceedings of conference on evaluation in medical education. Edmonton: University of Alberta, 1971

8 Leonard C. The self-assessment of confidence, by one vocational trainee. $7 R$ Coll Gen Pract 1979;29.155-9.

Gough M, Bell J. Introducing aptitude testing into medicine. Br Med f 1989;298:975-6. 